\title{
ROLE OF STARCH CHARACTERISTICS IN THE PROPERTIES OF LOW-COST CERAMIC MEMBRANES
}

\author{
M-M. Lorente-Ayza ${ }^{a}$, M. J. Orts ${ }^{a}$, V. Pérez-Herranz ${ }^{b}$, S. Mestre ${ }^{a, *}$. \\ ${ }^{a}$ Instituto de Tecnología Cerámica. Universitat Jaume I. Castellón (Spain). \\ ${ }^{\mathrm{b}}$ IEC Group, Universitat Politècnica de València (Spain). \\ *Corresponding Author (sergio.mestre@itc.uji.es)
}

\begin{abstract}
Starch is used as porosity generator in membranes and other porous ceramics. There are different providers that offer a wide variety of starches, which produce distinct pore size distributions. A study was conducted to evaluate the effects of the characteristics of starches (impurities, particle size), obtained from potato, pea, maize and wheat, on the properties of microfiltration membranes formulated with traditional raw materials (the ceramic matrix was composed of quartz, albite and mullite). The results indicated that the pore size distribution and the permeability coefficient of the membrane can be controlled modifying only the particle size of starch. In this way, correlations were obtained between surface mean diameter of starch and membrane properties (characteristic pore diameters $\mathrm{d}_{16}$ and $\mathrm{d}_{50}$, and permeability coefficient). Moreover, it is necessary to use a starch having a mean particle size greater than about 50 microns in order to obtain a significant change in the pore size distribution and an increase in the permeability of the membrane.
\end{abstract}

Keywords: membrane, porosity, permeability, starch, particle size. 


\section{Introduction}

Ceramic porous materials have been a subject of research due to their potential applications in different types of membranes, as well as in other fields as catalyst supports $^{1}$, acoustic or thermal insulators ${ }^{2}$, and biomaterials ${ }^{3}$ among others.

The synthesis of porous ceramics frequently includes a substance which disappears during the thermal treatment of sintering (by decomposition, evaporation, melting or burning ${ }^{4}$ ), generating an additional network of pores that modify the membrane pore size distribution that could be obtained with the ceramic composition by itself. As examples, the melting and evaporation of poly(methylmetacrylate) described by Zeng et al. ${ }^{5}$, the decomposition of urea by Vijayan et al. ${ }^{6}$ or the burning of flour by Slosarczyk et al. ${ }^{7}$. The range of materials employed to create porosity in ceramics is broad, as the reviews about this subject have shown (Chevalier et al. $\left.{ }^{4}\right)$.

The addition of a temperature sensitive component in order to create porosity in the support is applied in the manufacture of membranes based on advanced ceramics (alumina, titania, zirconia), and also of membranes based on traditional compositions ${ }^{8}$ or local raw materials (clays ${ }^{9,10}$, perlite ${ }^{11}$ ). Numerous materials have been used as pore generators, starting by chemically pure substances (urea ${ }^{6}$ ), going through processed substances (corn $\operatorname{starch}^{11}$ ), and ending in natural products (poppy seeds ${ }^{2}$, rice bran $^{10}$ ), or even in wastes (sawdust ${ }^{8}$, fly $\operatorname{ash}^{9,12}$ ). Starches are broadly employed as materials for generating porosity in ceramics as they produce pores during burning out around $500^{\circ} \mathrm{C}^{13-15}$. In addition, they are easy to burn, cheap and environmentally friendly ${ }^{4}$. However, starch, as a substance derived from natural sources (potato, pea, corn, wheat, etc.) and subjected to different processes of extraction and conditioning, has a wide range of characteristics that can affect the final properties of the resulting membrane. 
Usually, in each research about membranes only one specific type of starch is used as pore generator. Therefore, this specific type of starch it is a fixed parameter along the investigation. However, the availability of different types of starch opens the door to modify the properties of membranes without changing the raw material's proportions or the processing parameters during the experiments, as shown Gregorova et al. ${ }^{16}$. One of the most interesting properties of a membrane is the permeability coefficient that is related with the geometry of the membrane's pore network. Many models have been proposed, based on different approximations, in order to relate the permeability of a porous solid with the characteristics of its own pore network. Some models are simple

like the Hagen-Poiseuille or the Kozeni-Carman equations ${ }^{17}$. However, the complexity of the model grows as the description of the pore network geometry became more rigorous (as examples, the application of grain models ${ }^{18}$ or digitized structure models ${ }^{19}$ ). In consequence, the phenomenological approaches remain of unique usefulness for the quantification of membrane's final properties ${ }^{20}$.

This research was focused on analyzing the effects of different types of starches, with distinct characteristics, on the properties of low-cost ceramic microfiltration membranes. The aim was to extend the range of membrane features (porosity, permeability), without modifying the proportions of the raw materials or the processing. Additionally, an attempt was made to relate membrane's permeability with the particle size of the specific type of starch used as pore generator through a simple model.

\section{Experimental}

The raw materials of the ceramic membranes were clay (UA-50, Mineraria, Spain), micronized sodium feldspar (courtesy of Pamesa, S.A. Spain) and feldspatic sand (AFS- 
125, Imerys, Spain). They were proportioned by weight in 40:40:20 ratios respectively. As a result, the global mixture was approximately $72.0 \mathrm{SiO}_{2}, 17.6 \mathrm{Al}_{2} \mathrm{O}_{3}, 4.2 \mathrm{Na}_{2} \mathrm{O}, 1.5$ $\mathrm{K}_{2} \mathrm{O}, 0.6 \mathrm{TiO}_{2}, 0.5 \mathrm{Fe}_{2} \mathrm{O}_{3}, 0.3 \mathrm{CaO}$ and $0.2 \mathrm{MgO}$, with a loss on ignition of 2.9 (wt $\%$ ). Six different starches were selected as pore generators: S1 (potato starch, Roquette Freres S.A., France), S2 (potato starch, Sigma-Aldrich Co. USA), S3 (wheat starch, Roquette Freres S.A., France), S4 (pea starch, Roquette Freres S.A., France), S5 (pea fiber L50M, Roquette Freres S.A., France), and S6 (maize starch extra pure, Fisher Chemical, USA). The above raw materials were processed as received, in powdery state. In addition, a supplementary pore generator was prepared by sieving the S6 starch through a 200 microns mesh that was named S7.

The particle size distribution of the starches was obtained by dry laser diffraction (master sizer 2000, Marvern Instruments Ltd. UK) and the characteristic diameters $\mathrm{D}_{10}$, $\mathrm{D}_{50}, \mathrm{D}_{90}, \mathrm{D}_{\mathrm{V}}$ and $\mathrm{D}_{\mathrm{S}}$ were calculated. The parameters $\mathrm{D}_{90}, \mathrm{D}_{50}$ and $\mathrm{D}_{10}$ are the cut off particle size below which $90 \%, 50 \%$ and $10 \%$ of the total particle volume lies. The parameters $D_{V}$ and $D_{S}$ are respectively the volume mean diameter and the surface mean diameter. The humidity was obtained from the weight loss after drying at $110{ }^{\circ} \mathrm{C}$ in an electrical oven ( $\mathrm{kg}$ of water by $100 \mathrm{~kg}$ of dry solid). The true density of the dried starches was measured by helium pycnometry (Ultrapycnometer 1000, Quantachrome Inc., USA.) and the ash content was determined by treating every starch at $1000{ }^{\circ} \mathrm{C}$. Finally, the chemical analysis of the ashes was performed by EDX (Genesis 7000 SUTW, EDAX, USA), connected to a FEG-SEM (Quanta 200F, FEI Co, USA). The ceramic raw materials were proportioned by weight and then dry mixed in a blade mill (Multitrio, Moulinex International, France). Once homogenized, the chosen starch was added gradually to the blade mill to avoid the formation of large agglomerates. All experiments were performed using mixtures calculated to contain $85 \mathrm{wt} \%$ of ceramic 
material and $15 \mathrm{wt} \%$ of dry starch (Table 1), except the reference mixture without starch (whose true density was measured by helium pycnometry). The volume fraction of starch was between $23 \%$ and $25 \%$ in all the raw material mixtures, and therefore beyond the percolation threshold of $18 \%$ indicated by Gregorová et $\mathrm{al}^{21}$. The eight mixtures were moistened up to a water content of $5.5 \mathrm{~kg} \mathrm{H}_{2} \mathrm{O} / 100 \mathrm{~kg}$ dry solid. Cylindrical test specimens of $50 \mathrm{~mm}$ diameter and 3-4 $\mathrm{mm}$ thickness were formed by uniaxial dry pressing at $300 \mathrm{~kg} \cdot \mathrm{cm}^{-2}$ and dried in an oven at $110^{\circ} \mathrm{C}$ no less than 24 hours. The bulk density of the green samples, and later of the sintered ones, was measured by mercury displacement.

The green specimens were sintered in two steps (figure 1). Initially, the starch was oxidised in a muffle furnace with a slow treatment characterised by a maximum temperature of $500{ }^{\circ} \mathrm{C}$ and a soaking time of 1 hour (K60L, Nannetti Spa. Italy). Finally, the specimens were sintered in a fast electric kiln (pirometrol S.A. Spain). This last thermal step was designed to balance the porosity and mechanical strength in the sintered membranes, and was characterized by a soaking time of 1 hour at $1100{ }^{\circ} \mathrm{C}$. The pore size distribution of the membranes was measured by mercury intrusion porosimetry (AutoPore IV 9500, Micromeritics Instruments Co, USA), and the open volume of pores and characteristic pore diameters $\left(\mathrm{d}_{16}, \mathrm{~d}_{50}\right.$, and $\left.\mathrm{d}_{84}\right)$, were calculated. The water uptake was measured by the boiling water immersion method and the permeability coefficient for water was obtained with a liquid permeameter (LEP101-A, PMI, USA). Additionally, the true density of the membranes was measured by helium pycnometry of milled samples, the mineralogical composition was obtained by XRD (D8 Advance, Bruker Co, USA), and the microstructure of some membranes was analyzed by FEG-SEM. 


\section{Results and discussion}

\subsection{Characterization of starches}

The humidity of the starches covered a fairly wide range (Table 2). In three of them, humidity was around $15 \mathrm{wt} \%$, while in other was clearly above, and in the two remaining, humidity was below. The true density of the starches S1, S2, S3, S4 and S5 was almost the same considering the uncertainty of measurement (Table 2), while this physical magnitude was significantly lower for starch S6. In spite of these differences, the processing of the raw material mixtures was accomplished as in the $\mathrm{C} 0$ composition. The ash content of the starches was less than $1 \mathrm{wt} \%$, except in the case of S5 which was markedly higher (Table 3), possibly due to its own production process, which incorporates greater proportion of impurities. By contrast, S2, S3 and S4 starches stand out for its low ash content. The ash content combined with EDX analysis provided the type and content of impurities. The results indicated that the starch S5 contains the greatest amount of impurities, followed by the starch S6 at a great distance. By contrast, starch S2 contained the lowest amount of impurities. The elements founded in greater proportions in the ashes were potassium, sodium, phosphorus and calcium. These elements could act as fluxes during the sintering of samples.

Particle size distributions of starches covered a rather broad range (Figure 2). The finest starches were S3 and S4, the coarsest were S5, S7 and S6, while particle size distributions of S1 and S2 occupied an intermediate position. The shape of the particle size distributions was symmetrical, except for S5, S6 and S7, which possessed a tail in the interval of lower diameters. The characteristic diameters indicated that the seven selected starches spanned an order of magnitude in particle diameter, taken as $\mathrm{D}_{50}$ (Table 4). From these results, it can be inferred that starch S3 should generate pores with diameter approximately one tenth of starch S6. Various options existed for $\mathrm{D}_{50}$ 
values less than half of the corresponding to $S 6$ starch, but a gap in $D_{50}$ values was detected between the obtained for S6 sample and the following commercial starch in size (S5). In order to cover this gap in $\mathrm{D}_{50}$ values, the starch $\mathrm{S} 7$ was prepared.

\subsection{Membrane characteristics}

The true density of starches and the mixture of ceramic raw materials $\left(2.64 \pm 0.02 \mathrm{~g} \cdot \mathrm{cm}^{-}\right.$ ${ }^{3}$ ), plus the data of bulk density of the green membranes allowed the estimation of their porosity $\left(\varepsilon_{\mathrm{G}}\right)$ (Figure 3$)$. The addition of starch causes a reduction in the bulk density of the green membrane. This is the result of lower true density of starch, together with the smaller compaction during pressing, as the porosity increases respect to the value corresponding to composition $\mathrm{C} 0$. In addition, starches' true density data allowed to discount the volume occupied by every starch in the green membranes simulating their state once the oxidation step of the thermal cycle has finished ( $\varepsilon_{\mathrm{GT}}$ in Figure 3$)$. It was found that $\varepsilon_{\mathrm{GT}}$ was practically independent of the starch employed. Accordingly, the porosity of the membranes at the start of the sintering step was nearly the same for all compositions except $\mathrm{C} 0$. This fact facilitated the assessment of the effects of starch's characteristics on the properties of membranes.

After sintering, membranes were obtained free of defects and with sufficient strength to perform characterization tests. It should be mentioned that other methods of preparing the mixture of raw materials caused defects in the membranes and thus were discarded (specifically, wet mixing and granulation were investigated). The sintered membranes were composed by quartz, albite and mullite (Figure 4), and showed a broader range of bulk densities than that of the green ones, which indicated that the effects of the voids left by starches during sintering had been different (Figure 5). The porosity and densification (defined as the change of porosity of the specimen as a consequence of 
sintering, divided by its initial porosity ${ }^{22}$ ) of synthesized specimens were calculated from the measured true density of the sintered membranes $\left(2.59 \pm 0.02 \mathrm{~g} \cdot \mathrm{cm}^{-3}\right)$. The results indicated that the addition of starches increased porosity and reduced densification in relation to the reference composition $\mathrm{C} 0$, but differences existed depending on added starch. Thereby, there is an approximately linear relationship with negative slope between densification and the particle size of starch (taken as $\mathrm{D}_{50}$, Figure 6), which is consistent with the increased difficulty in removing the largest pores during sintering. On the other hand, the impurity content of the starches did not seem to exert a significant effect on sintering, which is consistent with the high proportion of fluxes provided by the raw materials, but it could be an important factor for membranes based on high-purity oxides. In addition, SEM images (figure 7) showed that the microstructure of the supports considerably changed depending on the specific added starch. As an example, the $\mathrm{S} 2 \mathrm{starch}\left(\mathrm{D}_{50}\right.$ near the lower limit of the range explored) generated abundant rounded pores, and apparently with little direct interconnections (black areas in the image), while the coarsest starch S6 produced bigger pores, but less regular and apparently interconnected by openings of higher area.

The total pore volume, calculated from the bulk density of the ceramic matrix and the true density of the membranes, showed a very good correlation with the water uptake (Figure 8 ). The value of the slope, very close to 0.01 , indicates that practically all the porosity of the membranes was open. By contrast, mercury intrusion porosimetry always resulted in lower values of the open volume of pores, indicating that a fraction of the open porosity was below the detection limit of the equipment used ( 0.005 microns). This fraction of the open porosity was also a function of the added starch. Obviously, the employed starch affects the pore size distribution of the membrane modifying, among other features, the fraction of pores whose inlet is below the limit achievable by 
mercury intrusion. Broadly, the finer starches tend to increase the fraction of pores undetectable by mercury intrusion, but a direct correlation has not been identified, suggesting that the mixing process can affect to some extent the pore size distribution generated in the sintered membrane.

Membrane's pore size distribution showed bigger differences than those of porosity as a consequence of the effect of the starch (Table 5 and Figure 9). In general, the monomodal distribution of reference membrane $\mathrm{C} 0$ shifted to larger diameters and showed a trend to become bimodal for the membranes synthesized employing starch. This trend culminates in membranes C6 and C7, whose pore size distribution is bimodal. Despite this clear trend, a direct correlation was not detected between particle size distribution of the employed starch and pore size distribution generated in the membrane. It probably was due to differences in the physical basis of each measurement (light diffraction for particle size and mercury intrusion for pore size, and in this method the measured diameter corresponds to the pore inlet and not the real diameter of the pore). However, some correlations were identified between the characteristic diameters of particle and pore, which could be used to estimate the average pore size that a particular starch could generate in the membrane. Specifically, the best results were obtained by relating $\mathrm{D}_{\mathrm{S}}$ and pore diameters $\mathrm{d}_{16}$ or $\mathrm{d}_{84}$ with a quadratic polynomial (Figure 10). In addition, the $\mathrm{D}_{50}$ diameter of starches also showed a quadratic relation with the same characteristic pore diameters, but with slightly lower regression coefficients (they were not included by this reason). This parabolic trend means that to generate large pores in the membrane, or more correctly large pores whose inlet is also large, it is necessary to use starches with large particle size (for example, a starch with a $D_{S}$ of 60 microns would be required to generate a membrane with a $\mathrm{d}_{50}$ of 5 microns). However, the average particle size of most commercial starches is less than 40 microns, 
which is the interval of the curve where the effect of starch's particle size on the pore size of the membrane is smaller. The found equation is less time-consuming to obtain for a given system than the relation proposed by Gregorova et al. ${ }^{16}$ between the results of laser diffraction of starch and image analysis of 2D polished sections of the membranes.

The characteristics of the employed starches were clearly reflected in membrane's permeability coefficient, with changes of an order of magnitude (Table 5).

Consequently, membrane's permeability can be modified, while maintaining constant the proportion of starch in the mixture of raw materials, using starches with different particle size distribution. The measured flux through the membranes ranged from 580 to $8560 \mathrm{~L} \cdot \mathrm{m}^{-2} \cdot \mathrm{h}^{-1} \cdot \mathrm{bar}^{-1}$, interval over the limit of $50 \mathrm{~L} \cdot \mathrm{m}^{-2} \cdot \mathrm{h}^{-1} \cdot \mathrm{bar}^{-1}$ suggested for microfiltration membranes by Mulder ${ }^{23}$. This results are comparable to other experimental values for ceramic membranes $\left(815 \mathrm{~L} \cdot \mathrm{m}^{-2} \cdot \mathrm{h}^{-1} \cdot \mathrm{bar}^{-1}\right.$ for a membrane derived from perlite ${ }^{11}, 1440 \mathrm{~L} \cdot \mathrm{m}^{-2} \cdot \mathrm{h}^{-1} \cdot \mathrm{bar}^{-1}$ for a membrane obtained from $\mathrm{CaCO}_{3}$, quartz and $\mathrm{kaolin}^{24}$, and $17500 \mathrm{~L} \cdot \mathrm{m}^{-2} \cdot \mathrm{h}^{-1} \cdot \mathrm{bar}^{-1}$ for a membrane synthesized from an 80 $\%$ wt of clay and $20 \mathrm{wt} \%$ of $\left.\operatorname{starch}^{25}\right)$.

A simple model was investigated to relate membrane's permeability with the characteristics of the starch used, taking advantage of the relationship between the membrane's pore size and the surface mean diameter of starch. The Hagen-Poiseuille equation $^{17}(1)$ relates the permeability coefficient $\left(K_{P}\right)$ with the pore radius $(r)$, the water viscosity $(\eta)$, the surface porosity $\left(\varepsilon_{\text {sf }}\right)$ and the tortuosity factor $(\tau)$.

$$
K_{p}=\frac{\varepsilon_{s f}}{8 \eta \tau} r^{2}
$$

Assuming that the ratio $\varepsilon_{\mathrm{s}} / \tau$ varies little between the membranes, the model predicts an approximately linear relationship between $K_{p}$ and $r^{2}$. This trend was obtained for both 
$\mathrm{d}_{16}$ and $\mathrm{d}_{50}$ (Figure 11). However, the correlation was slightly better with the $\mathrm{d}_{16}$ parameter, which is logical, since the fluid preferentially flows through the pores of largest diameters. A $4^{\text {th }}$-order polynomial equation was expected to relate $\mathrm{D}_{\mathrm{s}}$ with $\mathrm{K}_{\mathrm{p}}$ as a result of combining the parabolic equation relating $D_{\mathrm{s}}$ and $\mathrm{d}_{16}$ with Hagen's equation, but a simpler quadratic equation was found to give a satisfactory correlation (Figure 12). This equation indicates that a starch of large particle size is necessary to increase the permeability of the membranes $\left(D_{s}>50 \mu m\right)$. As the most frequent $D_{s}$ of commercial starches lies between 20 and $50 \mu \mathrm{m}$, so they hardly modify the permeability. In consequence, it is necessary to select carefully the particle size of the starch in order to induce significant changes in the permeability.

\section{Conclusions}

Starches as a material of natural origin have a broad range of characteristics that influence their role as pore formers in microfiltration ceramic membranes.

Characteristics as water content, true density of dry starch, particle size distribution and impurity content varies between wide margins, and this variability of starch's characteristics can be reflected in the properties of membranes, both in green and sintered state.

The content of impurities does not seem to influence the final properties in the case of membranes based on traditional raw materials, while the particle size distribution is the characteristic that causes greater effects on the membrane. Specifically, as the starch particle size increases, the densification during sintering decreases, the pore size distribution shifts to larger diameters tending towards bimodality, and the porosity and the permeability coefficient increase. 
Variations in starch's particle size have been related to the membrane's final properties in most of the cases. In particular, the relation between $D_{S}$ and densification is approximately linear, whereas a quadratic relation was found with the permeability coefficient. As a result, it can be estimated that starches with a diameter greater than 50 microns $\left(a D_{s}\right)$ are required to exert a significant effect on membrane properties.

\section{Acknowledgements}

The authors thank Spanish Ministerio de Economía y Competitividad their support for the development of this research (Plan Nacional de I+D, ref. CTQ2012-37450-C02-02).

\section{Bibliography}

[1] Chandrappa G.T., Steunou N., Livage J. Macroporous crystalline vanadium oxide foam. Nature 2002; 416: 702.

[2] Gregorova E., Pabst W. Porous ceramics prepared using poppy seed as a pore forming agent. Ceram. Int. 2007;33:1385-8.

[3] Bae C.J., Kim H.W., Koh Y.H., Kim H.E. Hydroxyapatite bone scaffolds with controlled macrochannel pores. J. Mater. Sci.-Mater. M. 2006;17:517-21.

[4] Chevalier E., Chulia D., Pouget C., Viana M. Fabrication of porous substrates: A review of processes using pore forming agents in the biomaterial field. J. Pharm. Sci. 2008;97:1135-54.

[5] Zeng T., Dong X.L., Chen S.T., Yang H. Processing and piezoelectric properties of porous PZT ceramics. Ceram. Int. 2007;33:395-9.

[6] Vijayan S., Narasimman R., Prabhakaran K. A urea crystal templating method for the preparation of porous alumina ceramics with the aligned pores. J. Eur. Ceram. Soc. 2013;33:1929-34. 
[7] Slosarczyk A., Stobierska E., Paszkiewic Z. Porous hydroxyapatite ceramics. J. Mater. Sci. Lett. 1999;18:1163-5.

[8] Bose S., Das C. Preparation and characterization of low cost tubular ceramic support membranes using saw dust as a pore-former. Mater. Lett. 2013;110:152-5. [9] Seffaj N., Alami Younsi S., Persin M., Cretin M., Albizane A., Larbot A. Processing and characterization of $\mathrm{TiO}_{2} / \mathrm{ZnAl}_{2} \mathrm{O}_{4}$ ultrafiltration membranes deposited on tubular support prepared from Moroccan clay. Ceram. Int. 2005;31:205-10. [10] Mahmudul Hasan M., Shafiquzzaman M., Shafiul Azam M., Nakajima. J. Application of a simple ceramic filter to membrane bioreactor. Desalination 2011;276:272-7.

[11] Majouli A., Tahiri S., Alami Younssi S., Loukili H., Albizane A. Elaboration of new tubular ceramic membrane from local Moroccan perlite for microfiltration process. Application to treatment of industrial wastewaters. Ceram. Int. 2012;38:4295-303. [12] Cao J., Dong X., Li L., Dong Y.. Hampshire S. Recycling of waste fly ash for production of porous mullite ceramic membrane supports with increased porosity. J. Europ. Ceram. Soc. 2014;34:3181-94.

[13] Yang G.C.C., Tsai C. Effects of starch addition on characteristics of tubular porous ceramic membrane substrates. Desalination. 2008;233:129-36.

[14] Li S., Wang C., Zhou J. Effect of starch addition on microstructure and properties of highly porous alumina ceramics. Ceram. Int. 2013;39:8833-9.

[15] Topates G., Petasch U., Adler J., Kara F., Mandal H. Production and permeability of porous $\mathrm{Si}_{3} \mathrm{~N}_{4}$ ceramics produced by starch addition. Journal of Asian Ceramic Societies. 2013;1:257-61.

[16] Gregorova E., Pabst W., Bohacenko I. Characterization of different starch types for their application in ceramic processing. J. Europ. Ceram. Soc. 2006;26:1301-9. 
[17] Mulder, M. Basic principles of membrane technology $2^{\text {ed }}$. Kluwer academic publishers, Dordrecht. 1997. pp 169-172.

[18] Kainourgiakis, M.E., Kikkinides, E.S., Galani, A., Charalambopoulou, G.C., Stubos, A.K. Digitally reconstructed porous media: transport and sorption properties. Trans. Porous. Med. 2005; 58:43-62.

[19] Kikkinides, E.S., Stoitsas, K.A., Zaspalis, V.T., Burganos, V.N. Simulation of structural and permeation properties of multi-layer ceramic membranes. J. Membr. Sci. 2004; 243: 133-141.

[20] Burganos V.N. Modeling and simulation of membrane structure and transport properties, in: Drioli E., Giorno L. (Eds.), Comprehensive membrane science and engineering, Vol 1. Elsevier, Kidlington (UK), 2010, pp 29-73.

[21] Gregorová, E. Zivcová, Z., Pabst,W. Porosity and pore space characteristics of starch-processed porous ceramics. J. Mater. Sci. (2006) 41:6119-6122.

[22] German R. M. Sintering, theory and practice. John Wiley \& Sons, New York, 1996, pp 11-12.

[23] Mulder, M. Basic principles of membrane technology $2^{\text {ed }}$. Kluwer academic publishers, Dordrecht. 1997. pp 16-17.

[24] Vasanth, D., G. Pugazhenthi, G., Uppaluri, R. Fabrication and properties of low cost ceramic microfiltration membranes for separation of oil and bacteria from its solution. J. Membr. Sci. (2011) 379: 154- 163.

[25] Palacio, L., Bouzerdi, Y., Ouammou, M., Albizane, A., Bennazha, J., Hernández, A., Calvo, J.I. Ceramic membranes from Moroccan natural clay and phosphate for industrial water treatment. Desalination (2009) 245:501-507. 
Table 1: Composition of the mixtures (wt \% of raw materials and vol\% of ceramic and starch fractions).

\begin{tabular}{|c|c|c|c|c|c|c|c|}
\hline \multirow{3}{*}{ Ref. } & \multicolumn{5}{|c|}{ Raw materials } & \multicolumn{2}{|c|}{ Volume fraction } \\
\hline & \multirow{2}{*}{$\begin{array}{l}\text { Clay } \\
(\mathrm{wt} \%)\end{array}$} & \multirow{2}{*}{$\begin{array}{l}\text { Sodium } \\
\text { feldspar } \\
(\mathrm{wt} \%)\end{array}$} & \multirow{2}{*}{$\begin{array}{c}\text { Fedspatic } \\
\text { sand } \\
\text { (wt } \%)\end{array}$} & \multicolumn{2}{|c|}{ Starch } & \multirow{2}{*}{$\begin{array}{l}\text { Ceramic } \\
(\mathrm{vol} \%)\end{array}$} & \multirow{2}{*}{$\begin{array}{l}\text { Starch } \\
(\mathrm{vol} \%)\end{array}$} \\
\hline & & & & type & $\mathrm{wt} \%$ & & \\
\hline $\mathrm{C} 0$ & 40 & 40 & 20 & - & - & 100.00 & 0.00 \\
\hline $\mathrm{C} 1$ & 34 & 34 & 17 & $\mathrm{~S} 1$ & 15 & 76.46 & 23.54 \\
\hline $\mathrm{C} 2$ & 34 & 34 & 17 & $\mathrm{~S} 2$ & 15 & 76.48 & 23.52 \\
\hline $\mathrm{C} 3$ & 34 & 34 & 17 & S3 & 15 & 76.45 & 23.55 \\
\hline $\mathrm{C} 4$ & 34 & 34 & 17 & S4 & 15 & 76.45 & 23.55 \\
\hline $\mathrm{C} 5$ & 34 & 34 & 17 & S5 & 15 & 76.25 & 23.75 \\
\hline C6 & 34 & 34 & 17 & S6 & 15 & 74.65 & 25.35 \\
\hline $\mathrm{C} 7$ & 34 & 34 & 17 & S7 & 15 & 74.65 & 25.35 \\
\hline
\end{tabular}

Table 2: Moisture content of the starches and its true density after drying.

\begin{tabular}{|c|c|c|}
\hline Starch & $\begin{array}{c}\text { Moisture } \\
(\mathrm{wt} \%)\end{array}$ & $\begin{array}{c}\text { True density } \\
\left(\mathrm{g} \cdot \mathrm{cm}^{-3}\right)\end{array}$ \\
\hline S1 & 22.3 & $1.51 \pm 0.02$ \\
S2 & 16.8 & $1.51 \pm 0.02$ \\
S3 & 14.6 & $1.51 \pm 0.02$ \\
S4 & 14.6 & $1.51 \pm 0.02$ \\
S5 & 8.7 & $1.50 \pm 0.02$ \\
S6 & 9.9 & $1.37 \pm 0.02$ \\
\hline
\end{tabular}


Table 3: Ash and impurity contents of the starches.

\begin{tabular}{|c|c|c|c|c|c|c|c|c|c|c|c|}
\hline \multirow{2}{*}{ Starch } & \multirow{2}{*}{$\begin{array}{c}\text { Ash } \\
\text { content } \\
\text { (wt\%) }\end{array}$} & \multicolumn{7}{|c|}{ Impurities (mg/kg of dry starch) } \\
\cline { 3 - 10 } & Na & K & Mg & Ca & Zn & P & Cl & Cu & Si & Al \\
\hline S1 & 0.71 & 7 & 48 & 12 & 100 & 9 & 145 & - & 12 & 2 & - \\
S2 & 0.17 & 9 & 37 & 3 & 6 & 2 & 38 & - & 2 & 1 & - \\
S3 & 0.37 & 52 & 28 & 3 & 15 & 10 & 74 & - & 15 & 1 & - \\
S4 & 0.29 & 74 & 46 & 4 & 6 & 1 & 24 & - & 2 & 3 & - \\
S5 & 3.53 & 368 & 1198 & 119 & 207 & 0 & 108 & 41 & - & 9 & 3 \\
S6 & 0.83 & 274 & 14 & 5 & 17 & 23 & 38 & 38 & 26 & 2 & - \\
\hline
\end{tabular}

Table 4: Parameters of particle size distributions of the starches.

\begin{tabular}{|c|c|c|c|c|c|}
\hline Starch & $\begin{array}{c}\mathrm{D}_{10} \\
(\mu \mathrm{m})\end{array}$ & $\begin{array}{c}\mathrm{D}_{50} \\
(\mu \mathrm{m})\end{array}$ & $\begin{array}{c}\mathrm{D}_{90} \\
(\mu \mathrm{m})\end{array}$ & $\begin{array}{c}\mathrm{D}_{\mathrm{V}} \\
(\mu \mathrm{m})\end{array}$ & $\begin{array}{c}\mathrm{D}_{\mathrm{S}} \\
(\mu \mathrm{m})\end{array}$ \\
\hline S1 & 26 & 46 & 76 & 49 & 41 \\
S3 & 12 & 20 & 31 & 21 & 18 \\
S4 & 17 & 24 & 34 & 25 & 23 \\
S5 & 16 & 75 & 184 & 90 & 35 \\
S6 & 57 & 190 & 393 & 211 & 95 \\
S7 & 43 & 145 & 274 & 154 & 79 \\
\hline
\end{tabular}


Table 5: Pore size distribution parameters, water uptake and permeability coefficient of membranes.

\begin{tabular}{|c|c|c|c|c|c|}
\hline Ref. & $\begin{array}{c}\mathrm{d}_{16} \\
(\mu \mathrm{m})\end{array}$ & $\begin{array}{c}\mathrm{d}_{50} \\
(\mu \mathrm{m})\end{array}$ & $\begin{array}{c}\mathrm{d}_{84} \\
(\mu \mathrm{m})\end{array}$ & $\begin{array}{c}\text { Water uptake } \\
(\%)\end{array}$ & $\begin{array}{c}\mathrm{K}_{\mathrm{P}} \cdot 10^{16} \\
\left(\mathrm{~m}^{2}\right)\end{array}$ \\
\hline $\mathrm{C} 0$ & 1.5 & 1.2 & 0.8 & 8.4 & $\approx 0$ \\
$\mathrm{C} 1$ & 6.3 & 3.7 & 1.6 & 23.9 & $1.6 \pm 0.4$ \\
$\mathrm{C} 2$ & 6.1 & 3.6 & 1.6 & 22.4 & $1.4 \pm 0.2$ \\
$\mathrm{C} 3$ & 4.4 & 3.2 & 1.3 & 24.4 & $2.29 \pm 0.10$ \\
$\mathrm{C} 4$ & 4.7 & 2.9 & 1.5 & 23.4 & $1.67 \pm 0.12$ \\
$\mathrm{C} 5$ & 6.4 & 3.8 & 1.8 & 24.2 & $2.55 \pm 0.16$ \\
$\mathrm{C} 6$ & 17.6 & 9.5 & 2.5 & 28.9 & $23 \pm 2$ \\
$\mathrm{C} 7$ & 13.2 & 7.2 & 2.1 & 26.3 & $13.8 \pm 1.4$ \\
\hline
\end{tabular}




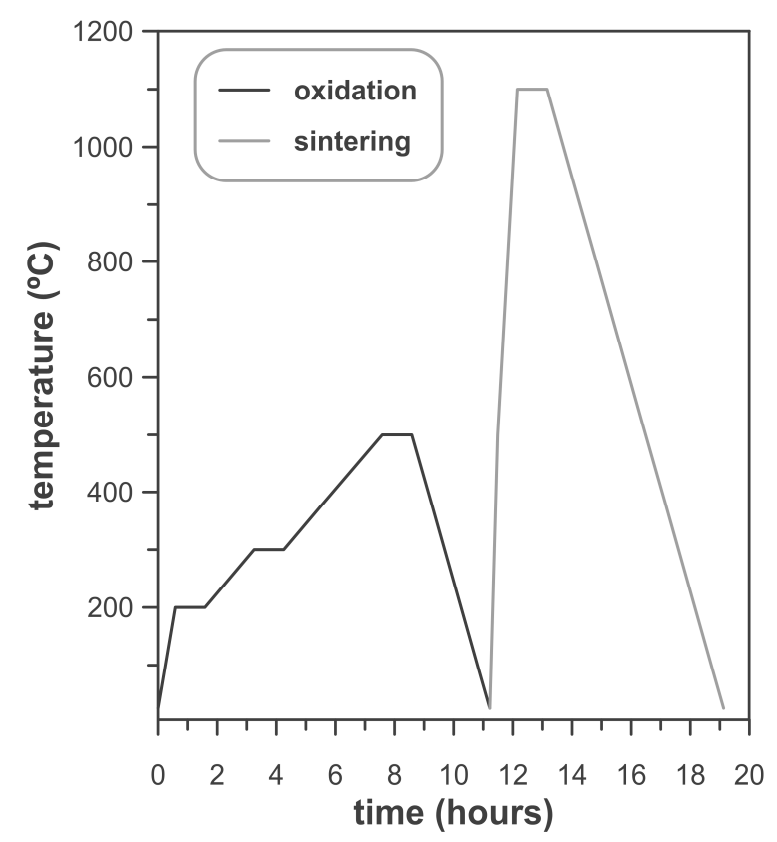

Figure 1: Thermal treatment employed for oxidizing the starch and sintering the membranes.
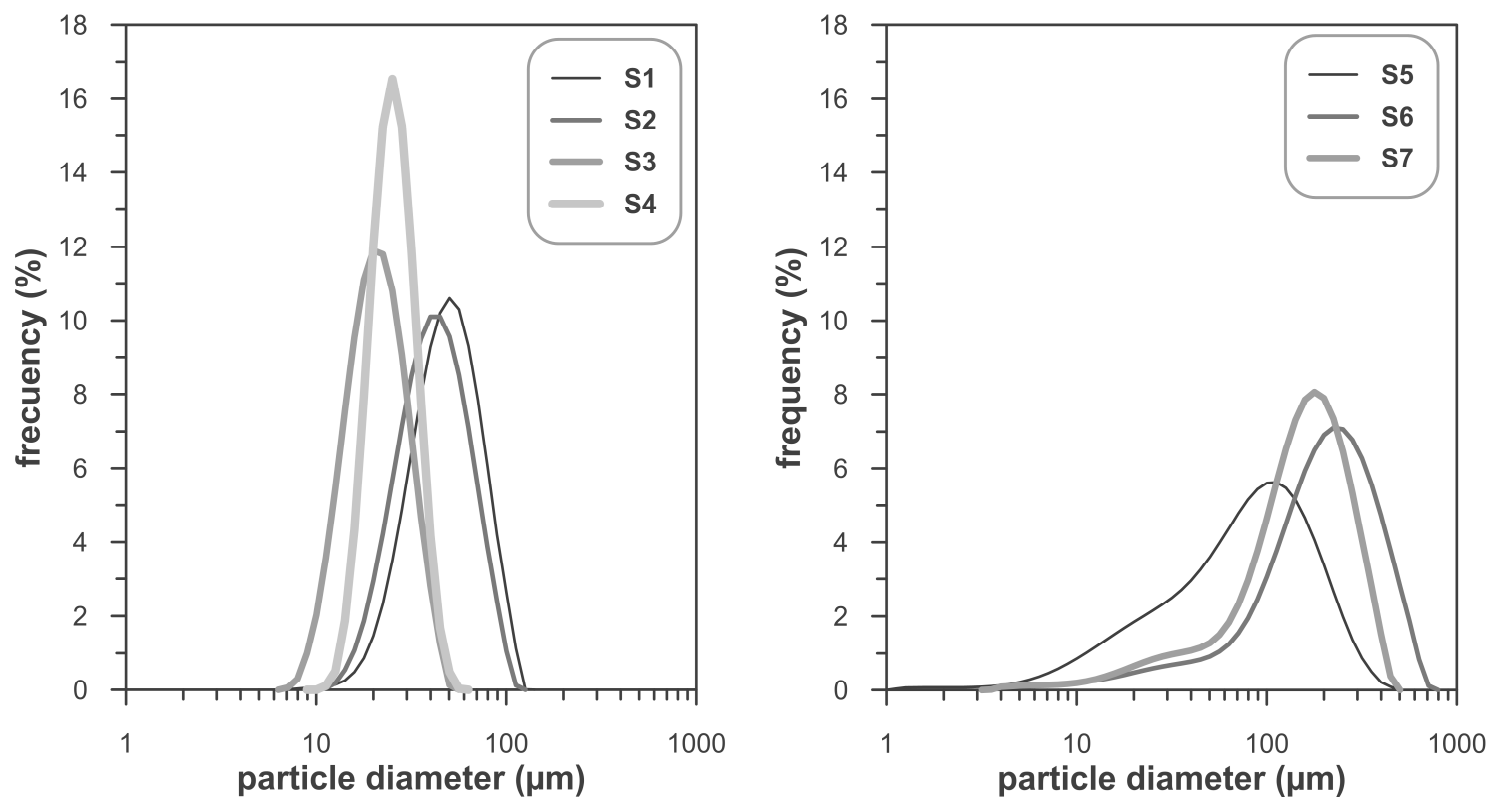

Figure 2: Starches' particle size distributions. 


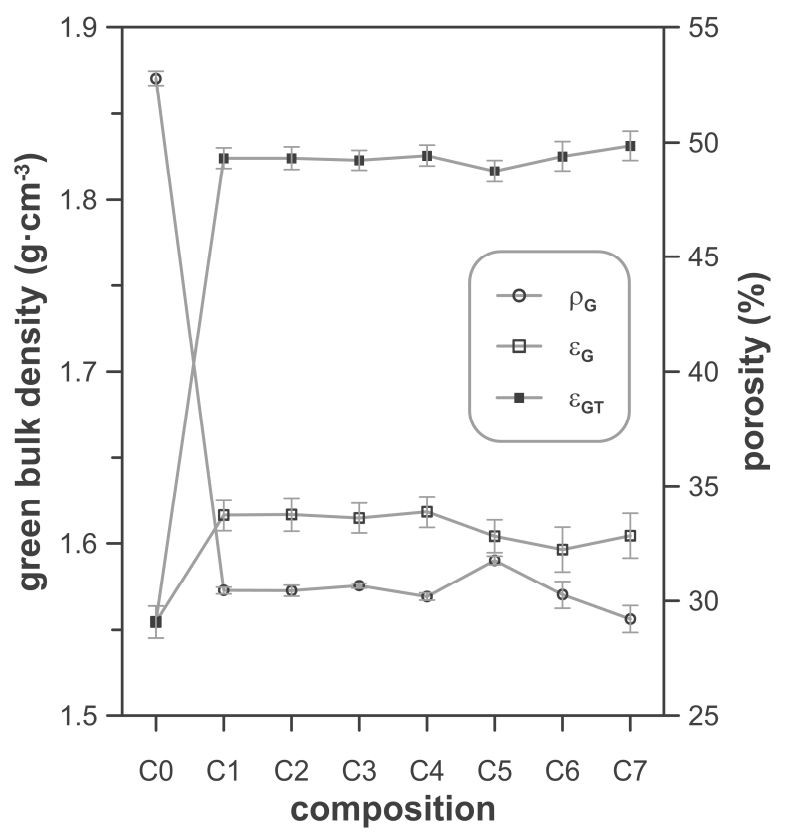

Figure 3: Measured bulk density $\left(\rho_{\mathrm{G}}\right)$ and porosity $\left(\varepsilon_{\mathrm{G}}\right)$ of green membranes, and also calculated porosity excluding the starch $\left(\varepsilon_{\mathrm{GT}}\right)$.

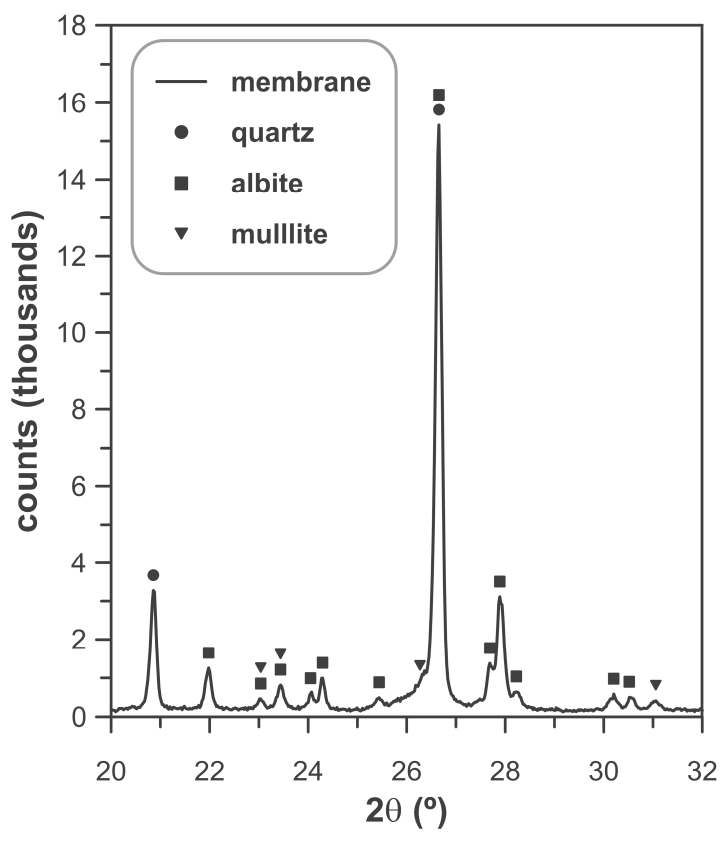

Figure 4: Diffractogram of membrane C0. 


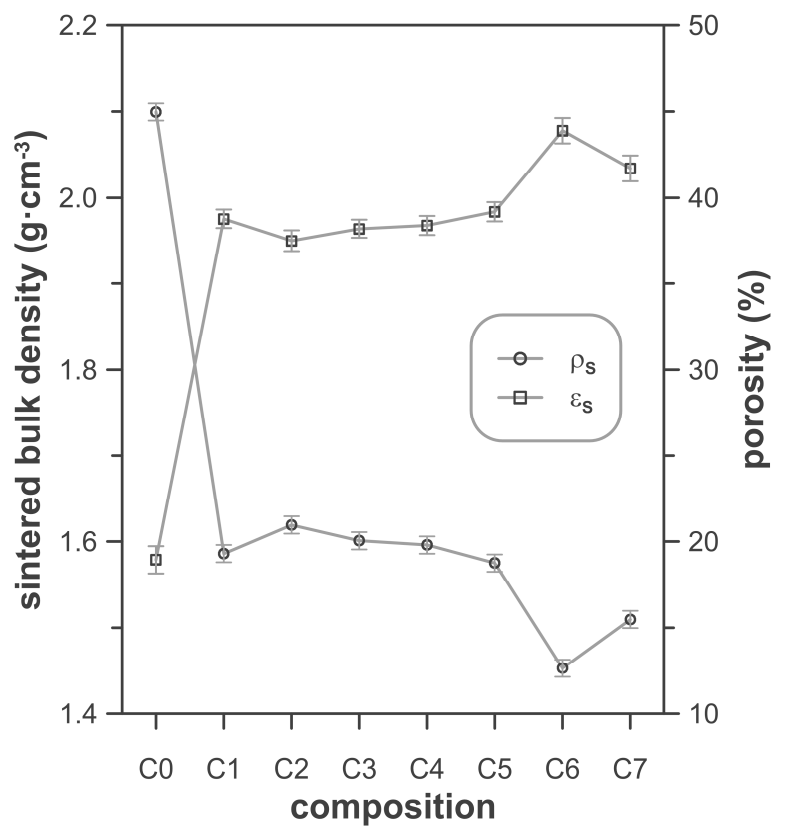

Figure 5: Bulk density $\left(\rho_{\mathrm{S}}\right)$ and porosity $\left(\varepsilon_{\mathrm{S}}\right)$ of sintered membranes.

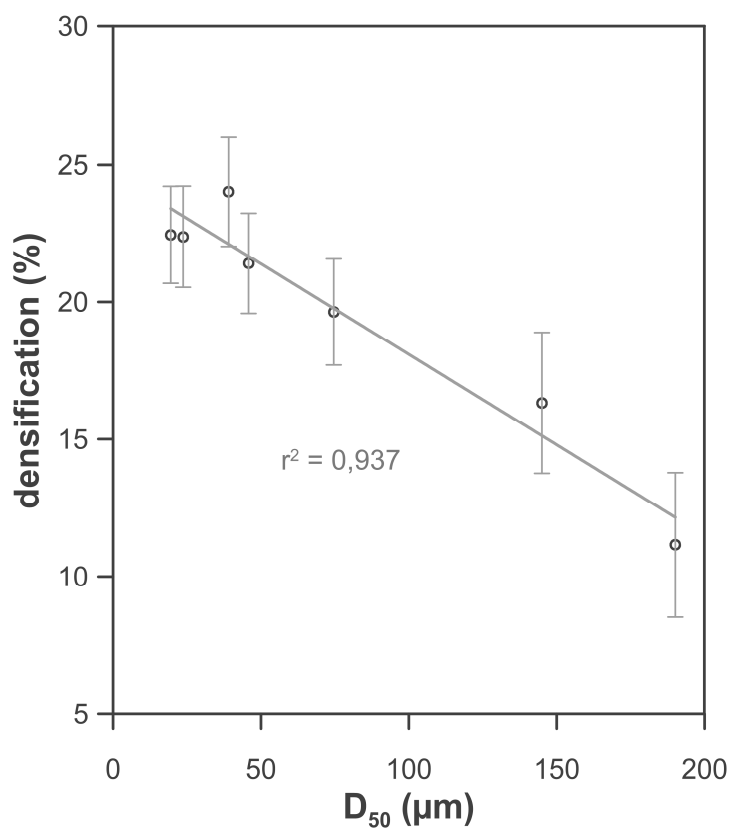

Figure 6: Relation between densification of sintered membranes and $\mathrm{D}_{50}$ of the employed starch. 


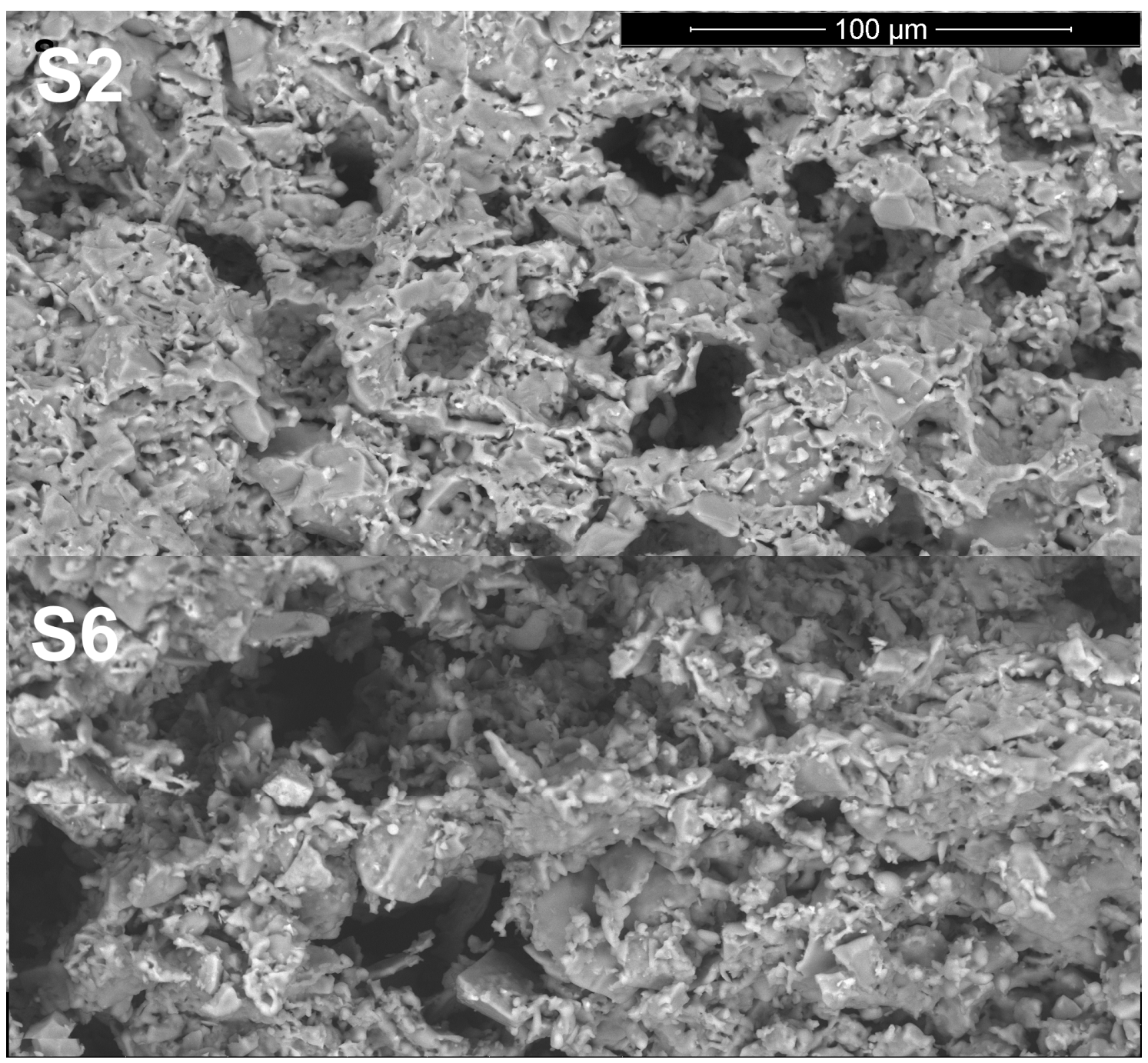

Figure 7: Microstructures of the membranes obtained from starches S2 and S6. 


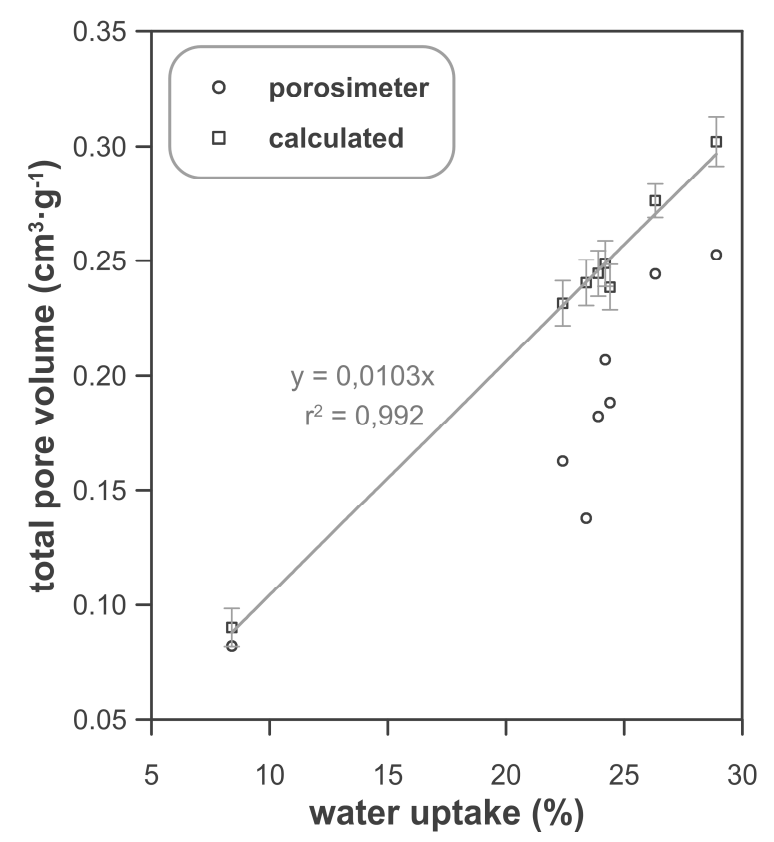

Figure 8: Relations between membranes' water uptake and the open pore volume measured by mercury porosimetry, and also the calculated total pore volume.
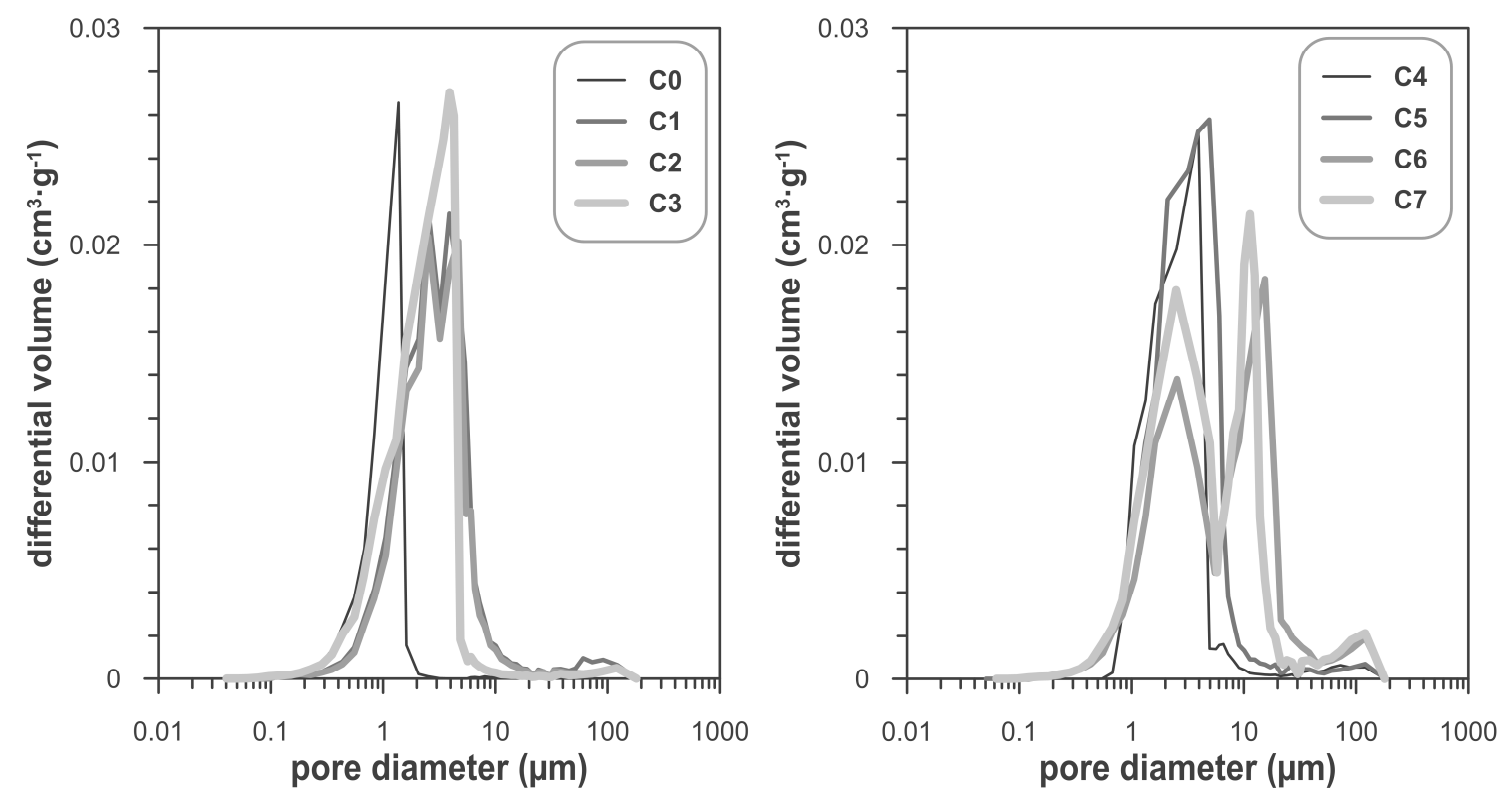

Figure 9: Differential pore size distributions of the membranes. 


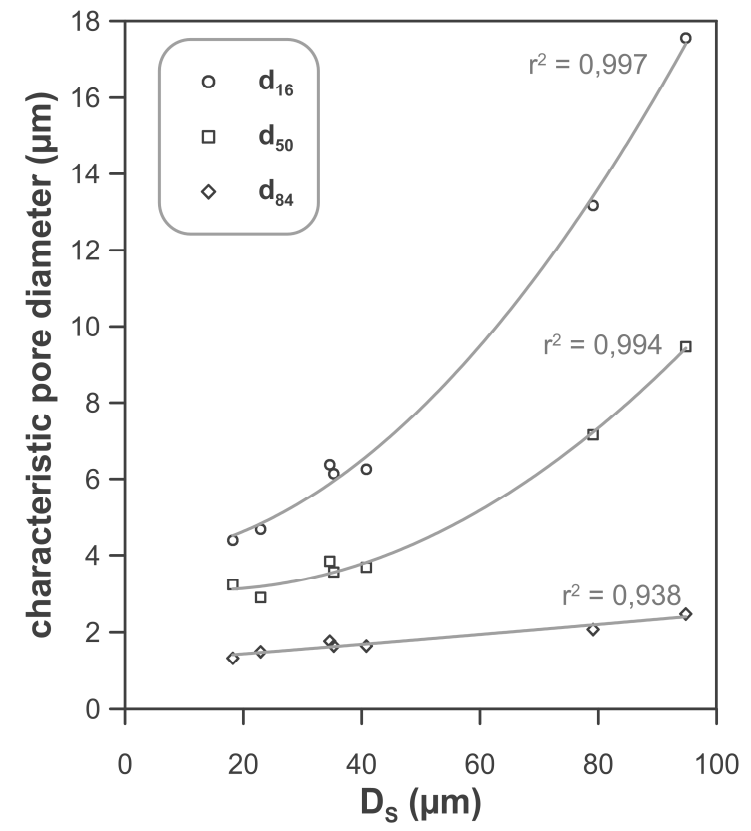

Figure 10: Relations between the characteristic pore diameters of the membranes and the surface mean diameter of the employed starch.

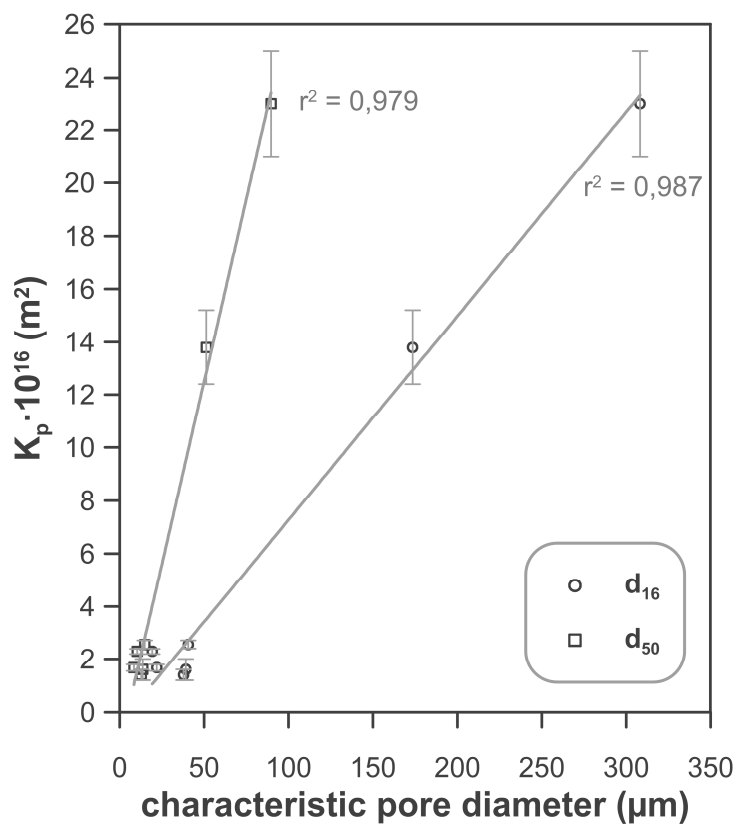

Figure 11: Relations between the permeability coefficient of the membranes and their characteristic pore diameters. 


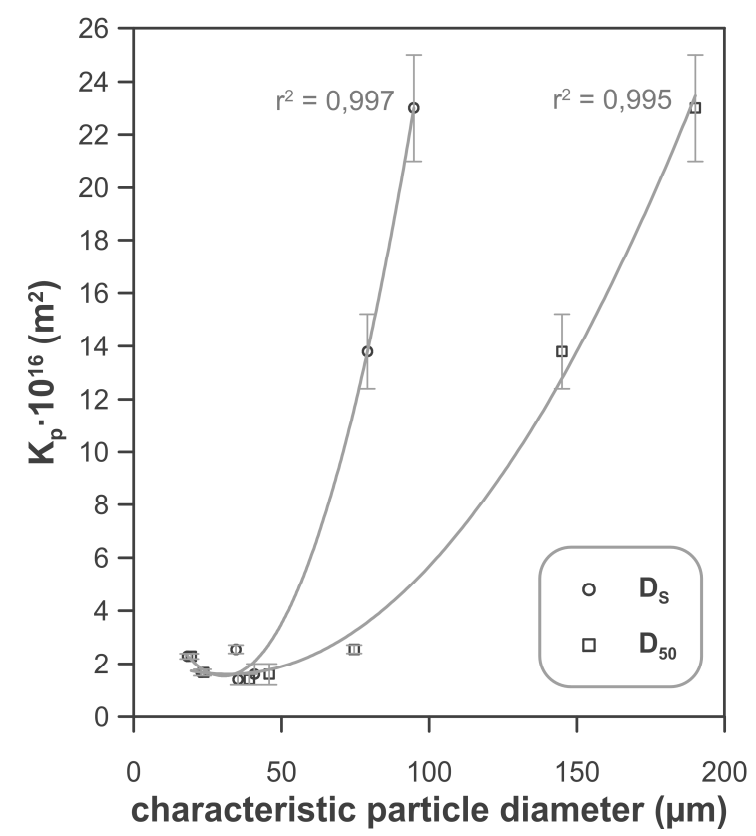

Figure 12: Relations between the permeability coefficient of the membranes and two characteristic particle diameters $\left(D_{S}\right.$ and $\left.D_{50}\right)$ of the employed starch. 